\title{
A System of Insolvency Prediction for industrial companies using a financial alternative model with neural networks
}

\author{
Callejón, A. M. \\ Department of Finance and Accounting \\ University of Malaga, 29071 (Spain) \\ e-mail: amcallejon@uma.es \\ Casado, A. M. \\ Department of Audiovisual Communication, Adversiting and Lit. \\ University of Sevilla, 29071 (Spain) \\ e-mail: acasado1@us.es \\ Fernández, M. A. \\ Department of Finance and Accounting \\ University of Malaga, 29071 (Spain) \\ e-mail: mangel@uma.es \\ Peláez J.I. \\ Department of Languages and Computer Sciences \\ University of Malaga, 29071 (Spain) \\ e-mail: jipelaez@uma.es \\ Received 7 June 2102; accepted 4 September 2012
}

\begin{abstract}
We find in the accounting literature the use of neural networks $(\mathrm{NN})$ for the prediction of insolvency data from the last financial year before the bankruptcy, with a success rate below $85 \%$. The objective of this work is to increase the predictive power of the NN models to discriminate between solvent and insolvent companies incorporating for this purpose a new set of financial ratios. A sample of about 500 European industrial companies that have filed for bankruptcy between 2007 and 2009 was confronted with about 500 solvent companies, matched by year, country and asset size. To do this, we have used five sets of different input data for training the NN. For each input set, $20 \mathrm{NN}$ have been trained for each number of neurons in hidden layer, from 1 to 50 neurons, giving a total of 5000 trained NN. The proposed model predicts correctly the 92.5 and 92.1 percent of the estimates of the training set and testing set (accuracy), respectively, using financial information for two years prior to bankruptcy.
\end{abstract}

Keywords: Bankruptcy prediction, Financials ratios, Credit risk, Neural networks.

\section{Introduction}

The accounting literature review on corporate insolvency prediction indicates that most studies conclude superiority in the ability to give a correct prediction for neural networks (NN) models, compared with other statistical techniques. It also follows that there is a high degree of uncertainty not only to implement the most efficient models, but also to determine the explanatory variables that compose them. In this context, experience and intuition are very important, so it is not surprising that the scientific and technological advance occurred in the field of $\mathrm{NN}$ does not go unnoticed for researchers to predict insolvency.

Today we can say that the NN has been established as an effective methodology for predicting bankruptcy. However, most of the authors estimate that their studies are preliminary and suffer from the lack of further development of technique and theory, especially in classification problems. As up to date, at applying NN models it has been used traditional radios which turn out to be optimum for the prediction of insolvency, we see it is necessary to try different input variables, never used before. Likewise, we will try to enrich the experiments with larger samples and varying the distribution of data in the training and testing process, since it can 
reduce the independence of the choice of the period of observation, analyzed sector and the size of the companies involved in the study. It is also required to try other network a architectures, avoiding in such a way, that the information used in the period of study, limited by the time and cost of the process, may put limits to the correct identification of the cases object of training. Also note that the accounting literature scarcest models that make predictions with financial data of two or more fiscal years preceding the date of bankruptcy. In addition, these studies decrease its ability to predict, with an accuracy that never exceeds $85.0 \%$ [1].

According to the above, the purpose of this paper is to contribute new empirical evidence on the ability of financial information to predict insolvent companies using NN. The novelties of this paper are: first, and although most predictive models were estimated with financial information for one year prior to bankruptcy, insolvency warning signs can appear before and therefore preventive action is needed as soon as possible. In this paper we obtain a prediction model using financial variables two years before bankruptcy with the ability to get a hit than $92.5 \%$, improving the existing results. Second, the sample coverage is extended to a more recent period, with experience covering business until 2009. Third, and considering that many bankruptcy studies used extrapolated samples to examine the actual predictive ability of their models $[2,3,4]$ the reliability of model has also tested with extrapolated data.

This paper is structured as follows: in addition to this introduction, Section 2 is a review of the literature. Then, in Section 3 the methodology is shown; variables and data used in the investigation are explained in Sections 4 and 5, respectively; and the results are stated in Section 6. Finally, completing the above, we present the main conclusions in Section 7.

\section{A Review of Bankruptcy Prediction Models}

\subsection{Early Empirical Approaches}

Among the pioneers of empirical studies on corporate bankruptcy prediction stand Beaver (1966) [5] and Altman (1968) [6], initially using the method of multiple discriminant analysis (MDA). The bankruptcy prediction model of Altman (1968) grew out of industrial information, and contained five financial ratios of an initial set of 22 variables. This model is able to predict correctly the status of $95 \%$ of the sample firms and $79 \%$ of the sample retention, one year before bankruptcy.
Since these early studies, further research has explained many factors that determine the insolvency or business failure worldwide. The number of explanatory factors used by them is in the range of 1 to 57, with an average value over the past 40 years ranging between 8 and 10, among which are the ratios "Income / Assets" and "Active Current / Current liabilities "as the most commonly used [1]. In summary, the conclusions obtained in this work highlight the importance of at least two factors in achieving financial balance: on the one hand, the proper correspondence between funding sources and nature of investments [6, 7]; and another, the company's ability to repay its debt using funds generated by the activity [8, 9, 10]. These findings allow to classify solvent and insolvent companies, but can also be used, not just two categories of companies, but different processes of business failure $[11,12]$.

Regarding the methodology, work has initially used almost exclusively MDA [6, 13, 14]. Subsequently, since the eighties, have also been applied Logit [3, 4, 7, 15, 16, 17] Probit [15, 18] and NN [7, 17, 19, $20]$.

Most of the work of insolvency prediction have used samples of U.S. firms [2, 3, 4, 5, 14, 21, 22] and British [17, 23, 24]. However, and to a lesser extent, companies in other countries have been studied. Such is the case of Swedish companies [18], or Italian companies [25] and Greek companies [15].

The conclusions of these papers argue that all models were successful in the correct classification of firms, with hit rates around $90 \%$, although in some cases Logit models and NN model outperformed the MDA. Theodossiou (1991) used statistical techniques Logit, Probit and MDA in the failure analysis of manufacturing firms in Greece. As in the investigation of Theodossiou, the study of Alici (1996) estimated a MDA, a Logit and NN applied to identify the failure of companies in the UK. It was confirmed that the Logit, Probit and MDA were higher than $\mathrm{NN}$ in predicting bankruptcy.

From the results obtained in previous research shows that the predictive power of the models decreases considerably when using financial information from more than one year prior to the bankruptcy of companies, with successes ranging from $72.0 \%$ [6] and $85.3 \%$ [21].

\subsection{Neural Networks Approaches}

NN techniques have been used successfully in numerous works on classification problems [26]. Besides bankruptcy, other issues have been addressed with NN methodology, such as 
inefficient management, capital structure, adverse economic effects and volatility [7]. From the empirical evidence shown by existing work, it can be concluded that Logit is the most widely used method for predicting corporate insolvency; indeed, this method gives a better success rate than the MDA, but never reached the levels obtained by NN.

The validation and efficiency of these conventional statistical methods depend to some extent on some restrictive hypothesis such as lineality, normality, independence among explicable variables, as well as on a previous functional form which relates the dependent variable with those explicable ones. These traditional methods are only appropriate when all statistical hypothesis are accomplished. Some studies show that NN are suitable instruments for the identification of the model object of analysis and they improve the classification due to its nonlineal and non-parametric features [34].

There are other reasons why the use of a non-lineal model would be superior to a lineal one. It has been argued that there are effects of saturation in the relation between financial ratios and the prediction of going bankrupt. For instance, if the changes incomes-active on the whole varied from $0,2,-0.1$ to 0.1 , it would have a major effect on the prediction that if the change in the ratio were from 1.0 to 1.2. It may also be argued that there are multiplying factors. For example, the potential of bankruptcy for a company with a negative cash-flow, is amplified if it has got a high range of debt. The reason for this is the difficulty that these firms have to get bank loans to finance their deficits [31].

A summary of the results obtained by the major studies that have used NN for bankruptcy prediction is listed in Table 1.

Table 1: Empirical evidence of bankruptcy prediction with NN (1 year).

\begin{tabular}{|l|c|c|}
\hline \multicolumn{1}{|c|}{ Authors } & Country & $\begin{array}{c}\text { Results (within } \\
\text { the sample) }\end{array}$ \\
\hline Tsukuda and Baba (1994) & JAPAN & $83.0 \%-100.0 \%$ \\
\hline Alici (1996) & UK & $73.3 \%-76.0 \%$ \\
\hline Sung et al (1999) & KOREA & $72.4 \%-90.0 \%$ \\
\hline Zhang et al (1999) & USA & $93.0 \%-97.0 \%$ \\
\hline Neophytou et al (2001) & UK & $95.83 \%$ \\
\hline Atiya (2001) & USA & $84.3 \%-81.4 \%$ \\
\hline Hu and Tseng (2005) & UK & $81.6 \%-78.3 \%$ \\
\hline Tsai and Wu (2008) & JAPAN & $88,0 \%-85.3 \%$ \\
& GERMANY & $79,0 \%-73,4 \%$ \\
& AUSTRALIA & $97,32 \%-84,6 \%$ \\
\hline Lin (2009) & TAIWAN & $86.4 \%-89.4 \%$ \\
\hline Zanganeh et al (2011) & IRAN & $96.2 \%-93.7 \%$ \\
& \multicolumn{2}{|c}{} \\
\hline
\end{tabular}

\section{Methods}

\subsection{Neural Networks}

NN are able to approximate non-parametric functions, and can reproduce the behaviour of any complex function with the desired degree of accuracy [7]. Artificial neural networks are named after trying to emulate biological systems. Typically consist of a series of composite layers by computational elements called neurons. The simplest model of neuron is the perceptron, which consists of a multi-input adder that applied to each a specific weight. So that it can be seen as a weighted adder. This sum is compared with the defined activation function; the most popular is the hyperbolic tangent sigmoid function. The perceptron output is a transformed response obtained from the weighted sum of inputs according to the configured output function. In this study, we have used the linear function.

The network topology known as multilayer perceptron (MLP) is a NN consisting of three layers of neurons, namely the input layer, the hidden layer, and the output layer. The first layer is the input one, and consists of as many neurons as inputs have the system. Meanwhile, the hidden layer can be formed, a priori, by any number of neurons. Finally, the number of neurons in the output layer is related to the number of needed outputs, in this case, a single neuron (solvent or insolvent).

The number of neurons in the hidden layer has been optimized experimentally, training $20 \mathrm{NN}$ for each number of neurons in hidden layer, starting from a single neuron and ending the experiment with 50 neurons in hidden layer. So, a total of $1000 \mathrm{NN}$ for each input set have been trained and the results have been compared to choose the number of neurons in hidden layer. As shown in Fig. 1 (accuracy), and Fig. 2 (Matthews' correlation coefficient), the number of neurons in hidden layer yields only a slight improvement for this work.

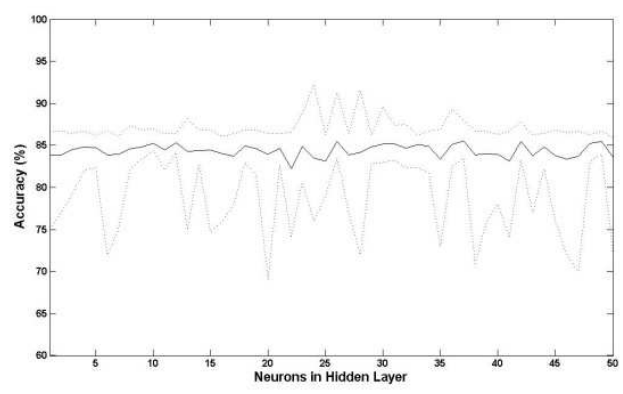

Fig. 1. NN Accuracy in experiment 2. 


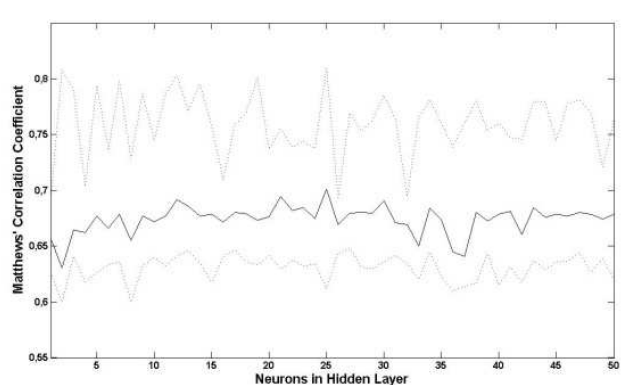

Fig. 2. NN Matthews' correlation coefficient in experiment 1.

Sensitivity, specificity and Matthews' coefficient were used as quality parameters of trained NN. The sensitivity estimates the system's ability to correctly identify the insolvent companies. A high sensitivity would indicate that the system correctly classified as insolvent the vast majority of the companies. However, it gives no information about the companies, that remaining solvent, but the system has wrongly classified as insolvent. An overly cautious network which scores most of companies as insolvent, whether they are such as if they are not, shows a high sensitivity value. The sensitivity of a binary classification system is calculated according to Eq. 1:

$$
\text { Sens }=\frac{\mathrm{TP}}{\mathrm{TP}+\mathrm{FN}}
$$

As Sens, is the system sensitivity, TP the number of insolvent companies correctly classified as insolvent (True Positives), FN the number of insolvent companies classified incorrectly as solvents (False Negatives).

The specificity of the system, in turn, represents the system's ability to correctly identify the companies that are solvent. A high specificity indicates that the system correctly classifies as solvents most of the companies which really are, however, as happened with the sensitivity, provides no information on the correct classification of the solvent companies. An overconfident network that marked as solvents most of the companies, whether they are such as if they are not, shows a high specificity value. The specificity of a binary classification system is calculated according to Eq. 2.

$$
\text { Spec }=\frac{\mathrm{TN}}{\mathrm{TN}+\mathrm{FP}}
$$

As Spec, is the system specificity, TN the number of solvent companies correctly classified as solvent (True Negatives), FP the number of firms classified incorrectly as insolvent (False Positives).
Therefore, to correctly evaluate the behaviour of a $\mathrm{NN}$ is essential to use both, the sensitivity and specificity, ensuring that both are as close as possible and show high values. To facilitate automatic evaluation of the trained networks, we have sought a third parameter of quality, the Matthews " correlation coefficient. This parameter increases as the sensitivity and specificity increase, and decreases when these values are distanced from each other. So an overconfident network (which marks most of the companies as solvents) shows a low sensitivity value and a high specificity value, while the Matthews' coefficient would be affected by this imbalance and shows a low value. Therefore, the Matthews' coefficient shows high values when the sensitivity and specificity are high and both show similar values. The Matthews' correlation coefficient can be calculated using Eq. 3.

\section{$\mathrm{MCC}=\frac{\mathrm{TP} \cdot \mathrm{TN}-\mathrm{FP} \cdot \mathrm{FN}}{\sqrt{(\mathrm{TN}+\mathrm{FP})(\mathrm{TN}+\mathrm{FN})(\mathrm{TP}+\mathrm{FP})(\mathrm{TP}+\mathrm{FN})}} \quad \mathrm{Eq} \cdot 3$}

As MCC, the Matthews' correlation coefficient.

During the training the weights of all neurons were adjusted according to the employed training algorithm. The back propagation algorithm of conjugate gradient was selected for this stydy, the early stop conditions were established as to achieve a minimum gradient of $1 \mathrm{e}-5$, or more than 6 consecutive errors. The gradient descent weight and bias function has been chosen as learning function, and as performance function, the mean square error.

For the NN training, total population was divided into three subgroups. The first one, comprising $70 \%$ of the companies studied was used for training itself. The second subgroup, comprising $15 \%$ of the companies was used as validation set for early stopping condition. And the third one, consisting of the remaining $15 \%$ of companies was used as a test group to verify the NN generalization ability.

\begin{tabular}{|c|c|c|c|c|}
\hline Threshold & Accuracy & Sensitivity & Specificity & $M C C$ \\
\hline 0,0 & 0,50 & 1,00 & 0,00 & 0,00 \\
\hline 0,1 & 0,70 & 0,99 & 0,41 & 0,50 \\
\hline 0,2 & 0,73 & 0,96 & 0,51 & 0,52 \\
\hline 0,3 & 0,76 & 0,95 & 0,57 & 0,56 \\
\hline 0,4 & 0,82 & 0,94 & 0,69 & 0,66 \\
\hline 0,5 & 0,92 & 0,93 & 0,90 & 0,84 \\
\hline 0,6 & 0,86 & 0,80 & 0,92 & 0,73 \\
\hline 0,7 & 0,75 & 0,58 & 0,92 & 0,54 \\
\hline 0,8 & 0,73 & 0,50 & 0,96 & 0,52 \\
\hline 0,9 & 0,63 & 0,28 & 0,99 & 0,39 \\
\hline 1,0 & 0,50 & 0,00 & 1,00 & 0,00 \\
\hline
\end{tabular}

Table 2. Thresholding 


\section{Financial Ratios and Econometric Variables}

There is no general agreement on the best set of financial ratios to be selected for the prediction of insolvency. In view of this, we have adopted an eclectic approach; initially using independent ratios suggested by the most common conclusions arising from the reviewed literature. The selected independent ratios were classified into four major categories discussed in the accounting literature, namely, financial stability, profitability, efficiency and firm size, as shown in Table 3.

Table 3. Financial ratios selection.

\begin{tabular}{|c|c|c|}
\hline Code & Classification & Equation \\
\hline$V F_{1}$ & $\begin{array}{l}\text { Liquidity and } \\
\text { solvency }\end{array}$ & $\begin{array}{l}\text { Current assets / Current } \\
\text { liabilities }\end{array}$ \\
\hline$V F_{2}$ & $\begin{array}{l}\text { Liquidity and } \\
\text { solvency }\end{array}$ & $\begin{array}{l}\text { (Cash \& Financial flows inv. } \\
+ \text { credits receivable) / Total } \\
\text { Debt }\end{array}$ \\
\hline$V F_{3}$ & $\begin{array}{l}\text { Liquidity and } \\
\text { solvency }\end{array}$ & EBIT / Current liabilities \\
\hline$V F_{4}$ & $\begin{array}{l}\text { Liquidity and } \\
\text { solvency }\end{array}$ & Total debt / Total assets \\
\hline$V F_{5}$ & $\begin{array}{l}\text { Liquidity and } \\
\text { solvency }\end{array}$ & $\begin{array}{l}\text { Equity / Non-current } \\
\text { liabilities }\end{array}$ \\
\hline$V F_{6}$ & $\begin{array}{c}\text { Liquidity and } \\
\text { solvency }\end{array}$ & EBIT / Total debt \\
\hline$V F_{7}$ & $\begin{array}{l}\text { Liquidity and } \\
\text { solvency }\end{array}$ & $\begin{array}{l}\text { (Net income + Depreciation } \\
\text { amortization and write-offs) / } \\
\text { Current financial liabilities }\end{array}$ \\
\hline$V R_{I}$ & Profitability & EBIT / Total assets \\
\hline$V R_{2}$ & Profitability & EBIT / Total revenues \\
\hline$V R_{3}$ & Profitability & Net income / Total income \\
\hline$V R_{4}$ & Profitability & Net profit / Total assets \\
\hline$V R_{5}$ & Profitability & $\begin{array}{l}\text { Financial expenses / } \\
\text { Payable to cost }\end{array}$ \\
\hline$V E_{1}$ & Efficiency & $\begin{array}{l}\text { Total income / Total } \\
\text { assets }\end{array}$ \\
\hline$V E_{2}$ & Efficiency & $\begin{array}{l}\text { Total income / Non- } \\
\text { current assets }\end{array}$ \\
\hline$V E_{3}$ & Efficiency & Intangibles / Total income \\
\hline$V E_{4}$ & Efficiency & Cash flow / Total assets \\
\hline$V D_{1}$ & Dimension & $\log$ Total Assets \\
\hline
\end{tabular}

The ratios which refer to the financial balance (VF1, VF2, VF4 and VF5) measure different liquidity degrees; while VF3 and VF6 measure the coverage of current liabilities and non-current with the operations benefits. Following $\mathrm{Kim}$ and $\mathrm{Gu}$ (2006), the latter ratios are measures of solvency because they indicate the ability of the company to use its net income from the operations to deal with their debts, combining short and long term.

Besides the six previous ratios, and in order to obtain a better measure of the company's ability to repay its debt, we have added a new indicator of solvency, VF7. Garcia and Fernandez (1992) argue that a good approximation to the problem of insolvency is achieved by detecting whether the level of resources generated by operations is insufficient to deal the indebtedness of a financial nature (not commercial). This perspective requires an analysis of the evolution of the company in terms of flows, mainly.

On the other hand, in reference to the ratios of profitability, Logue and Merville (1972) [27] proposed that the high cost reduces the chance of business failure, and therefore reduces the overall risk. According to Scherrer and Mathison (1996) [28], high profitability helps stabilize operating cash flows and reduce the risk of bankruptcy. Also $\mathrm{Gu}$ and Gao (2000) showed that unprofitable firms are more likely to end with a negative net worth and go bankrupt. In the present study, VR1 measures the ability of investments to generate net operating revenues. VR2 and VR3 ratios refer to the relationship between profit and total income, which is an approximation to the profit margin, or also called return on sales. Meanwhile, VR4 approaches the return on assets, and VR5 the cost of financing.

The pre-selection of independent variables was completed with four efficiency ratios of operations. So VE1 and VE2 variables measure the relationship between assets used (inputs) and sales revenue achieved (outputs). These ratios approach the rotation of current assets and non-current assets in terms of income generation. Logue and Merville (1972) suggested a negative effect on the efficiency in the risk of non-payment, arguing that firms with high efficiency tend to generate higher profits and therefore have less chance of failure. Finally, in order to control our model with the size of companies, a size variable has been included, VD1.

Once the preliminary selection of financial ratios is done, and to determine the final set of independent variables included in the model, we have developed five experiments. Experiment 1, uses a total of 23 econometric variables (Table 3 ) which are obtained directly from the accounting information provided by the companies in the sample. Experiment 2, derived from the learning achieved in the previous experiment, selected the 8 most significant variables by self-organizing map (SOM). Experiment 3, meanwhile, ordered a set of 16 previous financial ratios commonly used in the literature ad-hoc. Experiment 4 considered, in addition, the ability to return from the financial liabilities, thus adding a new ratio at 16 from the previous experiment. Finally, Experiment 5 contrasts the predictive power of the model using the best set of ratios which can be deduced from the experience gained in all previous experiments. 
Table 4. The 23 econometric variables.

\begin{tabular}{|c|c|c|}
\hline Non-current assets & $\begin{array}{l}\text { Shareholders' } \\
\text { Funds }\end{array}$ & $\begin{array}{l}\text { Liabilities: } \\
\text { creditors }\end{array}$ \\
\hline Intangible assets & $\begin{array}{c}\text { Statement for the } \\
\text { period }\end{array}$ & Other liabilities \\
\hline Current assets & $\begin{array}{l}\text { Profit and Loss } \\
\text { (P\&L) }\end{array}$ & Operating income \\
\hline Realizable assets & $\begin{array}{c}\text { Passive } \\
\text { unenforceable }\end{array}$ & Financial expenses \\
\hline Chargeable assets & $\begin{array}{c}\text { No long-term } \\
\text { liabilities }\end{array}$ & Taxation \\
\hline Available assets & Current liabilities & Amortization \\
\hline Cash & Liabilities: Loans & Depreciation \\
\hline Total assets & Current Loans & \\
\hline
\end{tabular}

\section{Data}

For the selection of the sample it has been aware that, at European level, we found no single definition of bankruptcy, since it is each country that shall establish and determine the insolvency proceedings and their effects. However, although each country has its own rules in this area, they are always homogenized according to the Regulation of the European Community 1346/2000 on insolvency proceedings, which necessarily have to adapt. Under this regulation, our industry base consists of insolvent companies that are legally classified as "bankruptcy".

We used information from a sample of 1000 European industrial companies between 2007 and 2009, comprising 500 insolvent companies and for 500 currently active (Table 4), in estimating the model prediction of insolvency, and demanding that the results were consistent. Furthermore, in order to make a contrast test the model with firms outside the sample, we selected 140 new European industrial companies (70 insolvent and 70 solvent) with the characteristics listed in Table 5 and 6 . The financial information used for insolvent companies has been referred to two years preceding the date of insolvency. Insolvent companies in the sample have been paired with solvent companies in terms of asset size, year and country.

Table 5. Sample structure of the industrial companies used to estimate.

\begin{tabular}{|l|r|r|r|r|r|c|}
\hline & \multicolumn{3}{|c|}{ Insolvents } & \multicolumn{3}{c|}{ Solvents } \\
\hline Country & Companies & \multicolumn{1}{|c|}{$\%$} & \multicolumn{1}{c|}{ Assets } & Companies & \multicolumn{1}{c|}{$\%$} & \multicolumn{1}{c|}{ Assets } \\
\hline Germany & 116 & 23.24 & 58078830 & 116 & 23.24 & 68132908 \\
\hline Denmark & 7 & 1.54 & 30139950 & 7 & 1.54 & 27453320 \\
\hline Greece & 16 & 3.16 & 20062076 & 16 & 3.16 & 32619441 \\
\hline Italy & 128 & 25.55 & 32530007 & 128 & 25.55 & 27989215 \\
\hline France & 95 & 19.05 & 21201692 & 95 & 19.05 & 21330561 \\
\hline Spain & 95 & 18.96 & 28215779 & 95 & 18.96 & 19309221 \\
\hline Portugal & 10 & 1.92 & 22585345 & 10 & 1.92 & 28454500 \\
\hline Finland & 9 & 1.82 & 39084590 & 9 & 1.82 & 51203011 \\
\hline Belgium & 24 & 4.75 & 3876791 & 24 & 4.75 & 3121299 \\
\hline Totals & 500 & 100.00 & 40343911 & 500 & 100.00 & 38904443 \\
\hline
\end{tabular}

Note: Total mean assets in euros.

Table 6. Sample structure of the industrial companies used as contrast test.

\begin{tabular}{|l|r|r|r|r|r|r|}
\hline & \multicolumn{3}{|c|}{ Insolvents } & \multicolumn{3}{c|}{ Solvents } \\
\hline \multicolumn{1}{|c|}{ Country } & Companies & \multicolumn{1}{c|}{$\%$} & \multicolumn{1}{c|}{ Assets } & \multicolumn{1}{c|}{ Companies } & \multicolumn{1}{c|}{ Assets } \\
\hline Germany & 22 & 23.24 & 58078830 & 22 & 23.24 & 51978211 \\
\hline Greece & 2 & 3.16 & 20062076 & 2 & 3.16 & 19321564 \\
\hline Italy & 23 & 25.55 & 32530007 & 23 & 25.55 & 29309899 \\
\hline France & 10 & 19.05 & 21201692 & 10 & 19.05 & 22771341 \\
\hline Spain & 9 & 18.96 & 28215779 & 9 & 18.96 & 32565301 \\
\hline Portugal & 1 & 1.92 & 22585345 & 1 & 1.92 & 22341990 \\
\hline Finland & 1 & 1.82 & 39084590 & 1 & 1.82 & 33341188 \\
\hline Belgium & 2 & 4.75 & 3876791 & 2 & 4.75 & 4898890 \\
\hline Total & 70 & 100.00 & 42878281 & 70 & 100.00 & 39456211 \\
\hline
\end{tabular}

Note: Total mean assets in euros.

Financial variables of firms in the sample have been obtained from the information provided by the database AMADEUS (Analyse Major Databases from European Sources), published by Bureau Van Dijk and made up a population of over 250000 European companies. That database provides information on key financial statements of companies (balance sheet, income statement and notes) for each year of study, required under accounting standards in the European Union.

The sample of selected companies has finally provided a vector index of 795 companies, of which 
477 intended for training, 159 to validation, and other 159 to test (Table 7).

Table 7. NN structure.

Solvency column-vector

Training matrix ( $N$ variables $x M$ companies)

Neural networks (20 iterations $x 50$ layers)

$>\quad$ Parameters of Neural network

$>\quad$ Output vector (795 companies)

$>$ Index vector:

- $\quad$ Training (477 companies)

- Validation (159 companies)

- Test (159 companies)

\section{Results and discussion}

The results for the different experiments are shown in Table 8. For each experiment, both training and testing results are shown. The optimal number of neurons in hidden layer is about 25 neurons with a relative deviation of $17 \%$, and the best threshold to maximice the Matthews' coefficient is between 0.4 and 0.5 .

The accuracy in all experiments are over $75 \%$, but the best results reach up to $92.5 \%$ (experiment 5 ). The best combination of sensitivity and specificity values are over $92 \%$ (experiment 5). Finally, the Matthews' coefficient is about 0.7 in the most of cases, but reachs up to 0.85 in the best case (experiment 5).

The selection of independent variables for bankruptcy prediction model is often the least discussed aspect of any study. As we discussed, financial theory does not indicate which variables should be included in the model. However, the set of variables selected by the model (VF3, VF5, VF7, VR1, VR4 and VD1) shows a high classification power. The results obtained with this set (Experiment 5) are shown in Table 8 along with the rest of experiments.

Table 8. System evaluation.

\begin{tabular}{|c|c|c|c|c|c|c|c|c|c|c|}
\hline \multirow[b]{2}{*}{ Parameters } & \multicolumn{2}{|c|}{ Experiment 1} & \multicolumn{2}{|c|}{ Experiment 2} & \multicolumn{2}{|c|}{ Experiment 3} & \multicolumn{2}{|c|}{ Experiment 4} & \multicolumn{2}{|c|}{ Experiment 5} \\
\hline & Train & Test & Train & Test & Train & Test & Train & Test & Train & Test \\
\hline $\begin{array}{l}\text { Neurons in } \\
\text { hidden layer }\end{array}$ & 25 & 34 & 26 & 37 & 24 & 22 & 31 & 31 & 26 & 26 \\
\hline Network & 18 & 19 & 9 & 16 & 2 & 3 & 17 & 4 & 1 & 18 \\
\hline Threshold & 0.5 & 0.5 & 0.4 & 0.4 & 0.4 & 0.5 & 0.6 & 0.6 & 0.5 & 0.4 \\
\hline Accuracy $(\%)$ & 86.02 & 77.37 & 85,42 & 78.01 & 88.45 & 80.33 & 88.97 & 88.12 & 92.56 & 92.11 \\
\hline Sensitivity (\%) & 85.81 & 93.63 & 100.00 & 94.64 & 80.26 & 71.42 & 84.42 & 83.02 & 94.88 & 94.69 \\
\hline Specificity (\%) & 86.24 & 61.05 & 70.81 & 61.43 & 96.62 & 89.21 & 93.40 & 93.07 & 90.28 & 89.66 \\
\hline $\begin{array}{l}\text { Matthews } \\
\text { coefficient }\end{array}$ & 0.72 & 0.57 & 0.74 & 0.59 & 0.77 & 0.61 & 0.78 & 0.76 & 0.85 & 0.84 \\
\hline
\end{tabular}

\section{Conclusions}

Following the NN methodology, this study develops a model to predict the failure of European industrial companies. So we've proposed a model MLP based in six independent input variables that showed for the test set a total accuracy of $92,11 \%$, a sensitivity of $94,69 \%$, and a specificity of $89,66 \%$ (so a 0,84 of MCC is obtained); hence results in a high accuracy rate, exceeding $92 \%$ in the classification of the sample, using information of two financial years prior to bankruptcy.
The obtained results with this set of financial variables suggest that the solvency is based, mainly, in the capacity to repay the debt with funds generated (VF3, VF7) and the level of profitability achieved (VR1, VR4) by the company itself. However, variables related to efficiency have been no significant. Therefore, the results of this study are in line with those obtained by Lin and Piesse (2004) [29], Hu and Tseng (2005) [30] y Atiya (2001) [31] on profitability, given that confrim the 
inverse relationship between the return on investment and teh risk of insolvency. Notwithstanding, the conclusions differ on other financial variables, such as the liquidity [30] and the efficiency [27], which do not provide the expected results. So the different selection of variables may be due to the caracteristics of the used sample, European companies, and it would be interesting to see in future works if this set of variables improves outcomes in companies of other nations and cultures.

The six input variables that make up the model suggest that financial policy for the industry should promote prudent capitalization of companies also seek to cover the debt of a financial nature with the resources generated by operations. Also it has been significant in explaining the insolvency variables returns on assets and firm size. Therefore, less capitalized industrial companies that fail to generate sufficient resources to meet its short-term borrowings with low cost and small size are most likely to incur in the event of bankruptcy.

It is also important to note that the creditors and, in particular, banks can use this MLP model as a tool to estimate an initial analysis to assess the creditworthiness of potential industrial customers (to measure credit risk). Should be especially cautious when processing applications and renewals lending entities in which the model predicts will fail. Meanwhile, companies can apply the model periodically as a financial check, in order to implement corrective measures in its business model to avoid a possible bankruptcy in the future.

An interesting point to note from the results is the importance of the variable VF7. A significant portion of short-term debt often accounts commercial debts, ie with suppliers. This commercial financing tends to remain as it is constantly renewed. By contrast, the other part of that liability, which refers to the financing bank or similar kind shows a different requirement in terms of depreciation, given the nature of this nonpermanent funds. Furthermore, the result of VF7 as significant ratio also suggests a more robust model to consider not only the EBIT as a source of funds to cover the liabilities, but more accurately, the ability to generate resources to meet those debts.

Further research on the differences in size can be important, given the preliminary findings of this study. Therefore, further research to small and medium enterprises (SME) could help improve financial management and to predict their risk of insolvency.

Signs of insolvency could appear several years before bankruptcy. As the prediction power of this model is 2 years prior bankruptcy, the companies can run preventive action with time to avoid the risk of bankruptcy.

\section{References}

[1] J. Bellovary, D. Giacomino and M. Akers, «A review of bankruptcy prediction studies: 1930 to present,» Journal of financial education, vol. 33, pp. 1-42, 2007.

[2] E. Altman, G. Marco and F. Varetto, «Corporate distress diagnosis: comparisons using linear discriminant analysis and network,» Journal of banking and finance, vol. 18, $\mathrm{n}^{\circ} 3$, pp. 505-529, 1994.

[3] C. Zavgren, «Assessing the vulnerability to failure of American industrial firms,» Journal of business and accounting, vol. 12, $\mathrm{n}^{\circ}$ 1, pp. 19-45, 1985.

[4] H. Kim and Z. Gu, «Bankruptcy: a logit model in comparison with a discriminant model,» Journal of hospitality and tourism research, vol. $30, \mathrm{n}^{\circ} 4$, pp. 474-493, 2006.

[5] W. Beaver, «Financial ratios as predictors of failure,» Journal of accounting research, vol. 5, pp. 71-111, 1966.

[6] E. Altman, «Financial ratios, discriminant analices and the prediction of corporate bankruptcy,» Journal of finance, vol. 23, $\mathrm{n}^{\circ}$ 4, pp. 589-609, 1968.

[7] G. Zhang, M. Hu, B. Patuwo and D. Indro, «Artificial neural networks in bankruptcy prediction: general framework and cross-validation analysis,» European journal of operational research, vol. 116, $\mathrm{n}^{\circ}$ 1, pp. 16-33, 1999.

[8] L. Bernstein and J. Wild, Analysis of financial statement, McGraw-Hill Companies, 1999, p. 381.

[9] J. Baldwin and G. Glezen, «Bankruptcy prediction using quaterly financial statement data,» Journal of accounting, auditing, and finance, vol. 7, pp. 269289, 1992.

[10] V. García and M. Fernández, Solvencia y rentabilidad de la empresa española, Madrid: Instituto de estudios económicos, 1992.

[11] S. Jones and D. Hensher, «Forecasting corporate bankruptcy: optimizing the performance of the mixed logit model,» Abacus, vol. 30, $\mathrm{n}^{\circ}$ 4, pp. 241264, 2007.

[12] J. Arquero, M. Abad and S. Jiménez, «Procesos de fracaso empresarial en Pymes. Identificación y contrastación empírica,» Revista internacional de la pequeña y mediana empresa, vol. 2, nº 1, pp. 64-77, 2009.

[13] R. Taffler, «The z-score approach to measuring company solvency,» The accountant's magazine, vol. 58, n² 2, pp. 91-96, 1983.

[14] Y. Mensah, «The differencial bankruptcy predictive ability of specific price level adjustments. Some empirical evidence,» The accounting review, vol. 58, $n^{\circ} 2$, pp. 228-246, 1983.

[15] P. Theodossiou, «Alternative models for assessing the financial condition of business in Greece,» 
Journal of business and accounting, vol. 18, $\mathrm{n}^{\circ} 5$, pp. 697-720, 1991.

[16] C. Arkaradejdachachai, Study of Corporate Turnaround: Using a Probability of Bankruptcy, Rolla: University of Missouri-Rolla, 1993, p. 154.

[17] P. Y. Alici, A. Moddy and A. Weigend, «Neural networks in corporate failure prediction. The UK experience,» Neural networks in financial engineering, pp. 393-406, 1995.

[18] K. Skogsviki, «Current cost accounting ratios as predictors of business failure. The Swedish case,» Journal of business, finance and accounting, vol. 17, $\mathrm{n}^{\circ} 1$, pp. 137-160, 1980.

[19] J. Tsukuda and S. Baba, «Predicting Japanese corporate bankruptcy in terms of financial date using neural networks,» Computers and industrial engineering, vol. 27, pp. 445-448, 1994.

[20] T. Sung, N. Chang and G. Lee, «Dynamics of modeling in data mining. Interpretive approach to bankruptcy prediction,» Journal of management information systems, vol. 16, $\mathrm{n}^{\circ}$ 1, pp. 63-85, 1999.

[21] J. Diamond, Pattern recognition and the detection of corporate failure, New York: University of New York, 1976.

[22] Z. Gu and L. Gao, «A multivariate model for predicting business failures of hospitality firms,» Tourism and hospitality research: the survey quarterly review, vol. 2, no 1, pp. 37-49, 2000.

[23] R. Tafler, «Empirical models for the monitoring of UK corporations,» Journal of banking and finance, vol. 8, nº 2, pp. 199-227, 1984.

[24] E. Neophytou and C. Miller, «Predicting corporate failure in the UK: a multidimensional scaling approach,» Journal of business, finance and accouting, vol. 31, $\mathrm{n}^{\circ}$ 5, pp. 677-710, 2004.

[25] A. Apetiti, «Identifying unsound firms in Italy. An attempt to use trend variables,» Journal of banking and finance, vol. 8, n 2, pp. 269-279, 1984.

[26] A. Dimitras, S. Zanakis and C. Zopounidis, "A survey of business failures with an emphasis on prediction methods and industrial applications,» European journal of operational research, vol. 90, pp. 487-513, 1996.

[27] L. Logue and J. Merville, «Financial policy and market expectations,» Financial management, vol. 1, no 3, pp. 37-44, 1972.

[28] P. Scherrer and T. Mathison, «Investment strategies for REIT inventories,» Real state review, vol. $26, \mathrm{n}^{\circ}$ 1, pp. 5-10, 1996.

[29] L. Lin and J. Piesse, «Identification of corporate distress in UK industrials: a conditional probability analysis approach,» Applied financial economics, vol. 14, pp. 73-82, 2004.

[30] Y. Hu and F. Tseng, "Applying backpropagation neuronal networks to bankruptcy prediction,» International journal of electronic business management, vol. 3, $\mathrm{n}^{\circ}$ 2, pp. 97-103, 2005.

[31] A. Atiya, «Bankruptcy prediction for credit risk using neural network: a survey and new results,» IEEE Transactions on neural networks, vol. $12, \mathrm{n}^{\circ} 4$, pp. 929-935, 2001.

[32] T. Linh, S. Osowsky and M. Stodolski, «On-line heart beat recognition using Hermite polynomials and neuro-fuzzy network,» Instrumentation and Measurement, IEEE Transactions on, vol. 52, $\mathrm{n}^{\circ} 4$, pp. 1224-1231, 2003.

[33] M. Hu, G. Zhang, B. Patuwo and D. Indro, «Artificial neural networks in bankruptcy prediction: general framework and cross-validation analysis,» European journal of operational research, vol. 116, no 1, pp. 16-33, 1999.

[34] F. Zahedi, «A meta-analysis of financial application of neural networks,» International journal of computational intelligence and organizations, vol. 1, n 3, pp. 164-178, 1996.

\section{Acknowledgements}

This investigation is allocated in the project of the Science and Innovation Minister TIN2011-26046. 